British Journal of Environment \& Climate Change

6(3): 159, 2016, Article no.BJECC.2016.015

ISSN: 2231-4784

SCIENCEDOMAIN international

www.sciencedomain.org

\title{
Part 2 - Water Services Provision and Climate Change Adaptation
}

\author{
Fayyaz Ali Memon ${ }^{1^{*}}$, J. O. Jenkins ${ }^{2}$ and S. Beatrice ${ }^{3}$ \\ (Guest Editors) \\ ${ }^{1}$ Centre for Water System, College of Engineering, Mathematics, and Physical Sciences, \\ University of Exeter, Exeter, UK. \\ ${ }^{2}$ Associate Dean International, School of Life and Medical Sciences, University of Hertfordshire, \\ C P Snow Building, College Lane, Hatfield, Hertfordshire, AL10 9AB, UK. \\ ${ }^{3}$ School of Mechanical \& Aerospace Engineering Queen's University Belfast, Room 05.019, Ashby \\ Building Stranmillis Road, Belfast BT9 5AH, UK.
}

Article Information

DOI: 10.9734/BJECC/2016/29154

Editorial

Received 25 $5^{\text {th }}$ August 2016

Accepted 25 $5^{\text {th }}$ August 2016

Published 25 ${ }^{\text {th }}$ August 2016

The uptake of innovative technical solutions and water services delivery models to address climate change uncertainties has been hampered by the fragmented nature of policies and the absence of an environment that recognises and then addresses the inherent complexity of the diverse stakeholder base involved in the provision and consumption of water services. Understanding the wider context and end user acceptability of innovations has the potential to improve the uptake and subsequent impact of solutions to the pressure facing the provision of water services, particularly when set against the backdrop of climate change.

This special issue focuses on the wider aspects which may contribute towards the delivery of sustainable water management and covers a range of topics including: user attitudes and perceptions to water demand management measures; approaches to understanding and influencing water end users, water-energy linkages and the interactions between community and water service delivery modes.

We hope readers will find the collection of presented papers informative, with them in turn contributing towards the development of new areas of research that lead to the development of relevant and impactful solutions. We would like to thank all contributing authors for their hard work and patience in the production of this special issue.

(C) 2016 Memon et al.; This is an Open Access article distributed under the terms of the Creative Commons Attribution License (http://creativecommons.org/licenses/by/4.0), which permits unrestricted use, distribution, and reproduction in any medium, provided the original work is properly cited.

${ }^{*}$ Corresponding author: E-mail: F.A.Memon@exeter.ac.uk; 